The influence of technology and risk management in the strategic synergy of a port system, International Symposium of the Analytic Hierarchy Process 2016, London, U.K.

\title{
THE INFLUENCE OF TECHNOLOGY AND RISK MANAGEMENT IN THE STRATEGIC ALIGNMENT OF A PORT SYSTEM
}

\begin{abstract}
This paper presents an ANP model for determining the influence of technology, risk management, and the relationships of actors participating in the operation of a publicprivate port system. The model is applied to the case of a medium size port community having several actors performing specific roles expressed in their strategic missions. With the aid of the model, it is possible to find dominant actors and criteria, which allow to establish a core of actors and strategic priorities contributing to the global synergy.
\end{abstract}

Keywords: strategic planning, ANP, system synergy, port systems.

\section{Introduction}

In a port system, there are several sources of risk caused by the strategic and operational links between a network of private companies, trade associations and social and labor groups and their macro-environment. The strength of those linkages can create synergy in the logistic chain in the sense that overall performance to minimize risk increases in comparison to a chain with weaker relationships. Similar with technology, specially ICT, by which the logistic chain and linked actors can optimize their performance (Durán \& Córdova, 2009). Most articles, however, are conceptual and do not address quantitatively the identification of the critical actors and dominant criteria in order to produce the strategic alignment needed for the overall optimization of performance. In this paper, an ANP model is proposed and it is applied to medium-size port system in Chile.

\section{Literature Review}

The synergy in a network of organizations and its relationships with the risk level that will assume each actor has been addressed by Wei (2010). With regard to technology, the synergy is achieved by sharing information, collective intelligence, specialized skills and tools that can be combined into an organized system characterized by technological innovation, quality improvements and e-business between players (Zhong et al., 2011). In this paper, ANP framework is used (Saaty, 2006).

\section{Objectives}

This paper aims at developing a quantitative method to identify the critical actors and dominant criteria in order to produce the strategic alignment needed for the overall optimization of a port system strategy.

\section{Research Methodology}

The method is based on the semantic interpretation of strategic missions of actors in the port system aided by focus group evaluations on an ANP framework. The ANP super matrix is built based on those evaluations in order to find the dominant actors and criteria. 
The influence of technology and risk management in the strategic synergy of a port system, International Symposium of the Analytic Hierarchy Process 2016, London, U.K.

\section{The Proposed Method}

Based on the system in Fig. 1 and Technology and Risk criteria the super matrix is built.

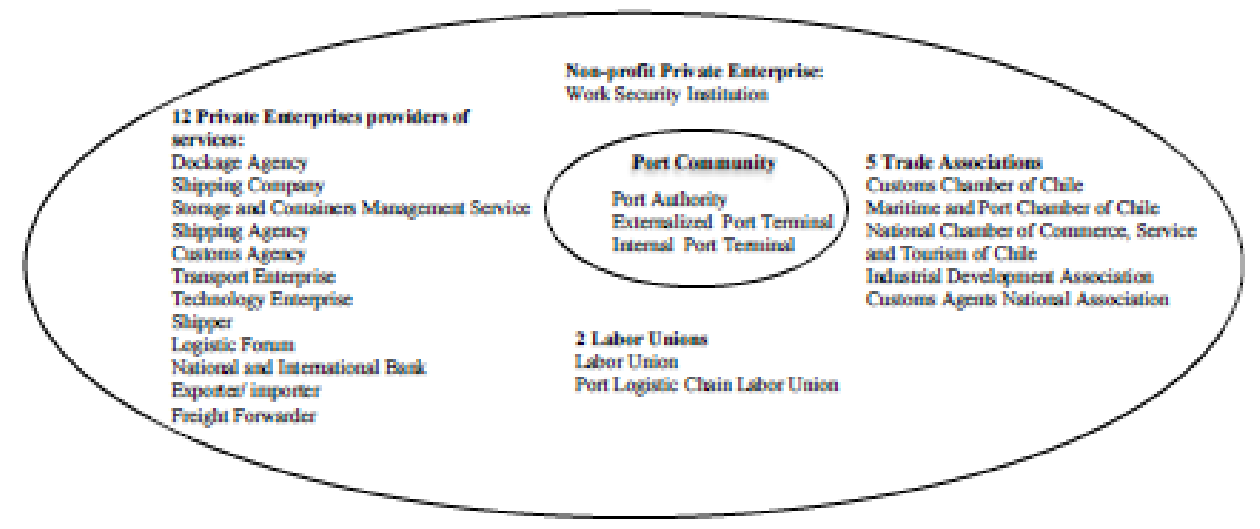

Figure 1. Actors comprising the port system in the case study.

\section{Limitations}

The main limitation of the method is the assumption of expert knowledge to express the degree of influence in pairwise comparisons. However, the paper proposes other methods based on direct evaluation of key performance indicators (KPI) in order to facilitate the judgments and their consistency.

\section{Conclusions}

A core of dominant port stakeholders is found. Actors of the port system who have more links are those that are closer to the core of the port business and need to be aligned in their strategies concerning risk and technology. Risk is the dominant criterion for the particular case. ANP is proved to be useful for identifying the critical core for synergy.

\section{Key References}

Durán, C. \& Córdova, F. (2009). Synergy and Technology Gaps in Export Logistics Chains between a Chilean and a Spanish medium-sized Port. Procedia Computer Science 55: 632-641.

Saaty, T. and Vargas, L. (2006). Decision Making with the Analytic Network Process: Economic, Political, Social and Technological Applications with Benefits, Opportunities, Costs and Risks. New York: Springer.

Wei, H. (2010). Cooperation and Competition of Interfirm Network Organizations: The Function of Synergies. The International Conference on E-Business and E-Government ICEE 2010, Guangzhou, China.

Zhong, M., Wu, Y. \& Luan, W. (2011). Model of synergy degree between port logistics and urban economy. Journal of Dalian Maritime University, 37(1), 80-82. 